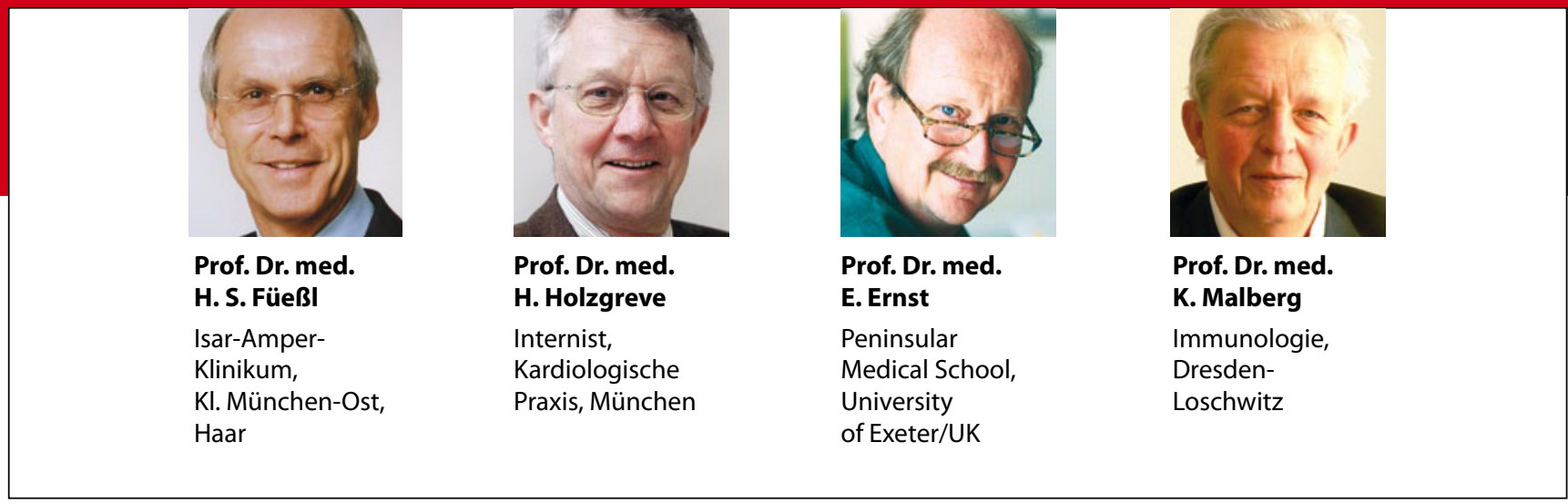

\title{
Lohnt es sich, Zwerge auf Normalmaß zu bringen?
}

\begin{abstract}
Körpergröße gilt vielen Eltern als wichtige Voraussetzung für das Lebensglück der Sprösslinge, dem man mit Wachstumshormonen auf die Sprünge helfen will, wenn die Kinder kleinwüchsig sind. Die Erfolge sind jedoch sehr bescheiden.
\end{abstract}

— Eine für das Alter zu geringe Körpergröße gilt als häufigster Überweisungsgrund an pädiatrische Endokrinologen. Obwohl es eine Reihe von definierten Krankheitsbildern mit geringer Körpergröße gibt, liegt bei den meisten Kindern doch ein idiopathischer Kleinwuchs vor. Diese Diagnose wird gestellt, wenn die Körpergröße mehr als zwei Standardabweichungen unter dem korrespondierenden Mittelwert von altersund geschlechtsgleichen Kindern in der Allgemeinbevölkerung liegt, ohne dass Hinweise für systemische, endokrine, ernährungsbedingte oder chromosomale Erkrankungen bestehen.

Obwohl die Behandlung mit Wachstumshormonen im ersten Behandlungsjahr zu einer deutlichen Größenzunahme führt, bestehen durchaus Zweifel, ob sich diese Therapie langfristig wesentlich auf die Körperlänge auswirkt und ob damit nicht unerwünschte Effekte, insbesondere die Induktion von Mali-

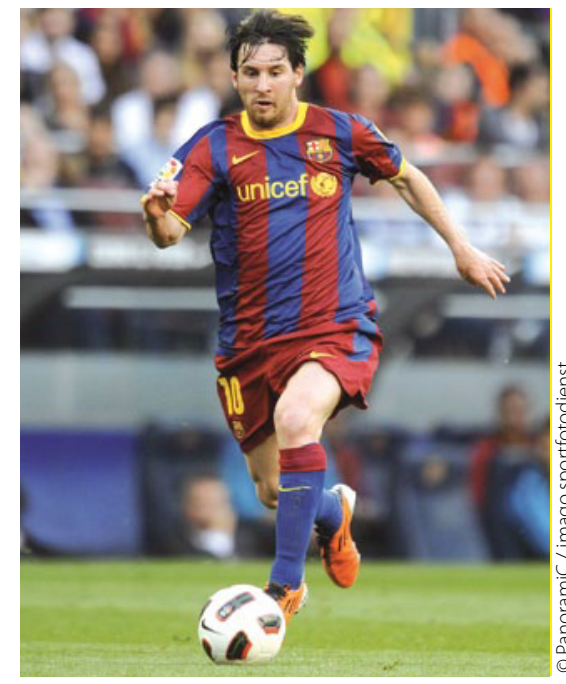

Als Spieler ein Gigant, körperlich trotz Hormonbehandlung eher klein: Lionel Messi.

gnomen, ausgelöst werden. Wegen dieser Zweifel haben die gesetzlichen Krankenkassen in den meisten Ländern diese Therapie von der Erstattung ausgeschlossen.

In einer systematischen Literatursuche nach randomisierten und nicht randomisierten kontrollierten Studien zwischen 1985 und April 2010 fand man drei randomisierte kontrollierte Studien mit 115 Kindern, die den Einschlusskriterien genügten. Die erreichte Endgröße im Erwachsenenalter überstieg die Körpergröße der Kontrollgruppe um 0,65 Standardabweichungen, was real einer Größenzunahme von $4 \mathrm{~cm}$ entspricht. Die durchschnittliche Längenzunahme der behandelten Kinder lag bei 1,2 Standardabweichungen im Vergleich zu 0,4 Standardabweichungen der unbehandelten Kinder.

\section{Kommentar}

Die Langzeituntersuchungen zeigen, dass sich Eltern von Kindern mit idiopathischem Kleinwuchs wahrscheinlich zu viel von der Therapie mit Wachstumshormonen versprechen. Tatsächlich ist der Größenzuwachs ziemlich bescheiden. Ob die Körpergröße für den Lebenserfolg, um den die meisten Eltern besorgt sind, tatsächlich von so großer Bedeutung ist, erscheint zumindest diskutabel. Für die Kostenträger und die Gesellschaft erhebt sich die Frage, ob ein medialer Größenzuwachs von $4 \mathrm{~cm}$ nach einer 5-6-jährigen Therapie mit Wachstumshormonen tatsächlich die jährlichen Kosten in Höhe von etwa $20000 €$ wert sind. Jeder dieser Zentimeter kostet im Durchschnitt $27000 €$.

H. S. FÜESSL =

\section{- A. Deodati, S. Cianfarani}

Impact of growth hormone therapy on adult height of children with idiopathic short stature: systemic review. Brit. Med. J. 342 (2011) c7157 